\title{
Role of Oxides and Porosity on High-Temperature Oxidation of Liquid-Fueled HVOF Thermal-Sprayed Ni50Cr Coatings
}

\author{
B. Song ${ }^{1} \cdot$ M. Bai ${ }^{1} \cdot$ K. T. Voisey $^{1} \cdot$ T. Hussain ${ }^{1}$
}

Submitted: 5 August 2016/in revised form: 11 January 2017/Published online: 31 January 2017

(C) The Author(s) 2017. This article is published with open access at Springerlink.com

\begin{abstract}
High chromium content in Ni50Cr thermally sprayed coatings can generate a dense and protective scale at the surface of coating. Thus, the Ni50Cr coating is widely used in high-temperature oxidation and corrosion applications. A commercially available gas atomized Ni50Cr powder was sprayed onto a power plant steel (ASME P92) using a liquid-fueled high velocity oxy-fuel thermal spray with three processing parameters in this study. Microstructure of as-sprayed coatings was examined using oxygen content analysis, mercury intrusion porosimetry, scanning electron microscope (SEM), energydispersive $\mathrm{x}$-ray spectroscopy (EDX) and x-ray diffraction (XRD). Short-term air oxidation tests $(4 \mathrm{~h})$ of freestanding coatings (without boiler steel substrate) in a thermogravimetric analyzer at $700{ }^{\circ} \mathrm{C}$ were performed to obtain the kinetics of oxidation of the as-sprayed coating. Long-term air oxidation tests $(100 \mathrm{~h})$ of the coated substrates were performed at same temperature to obtain the oxidation products for further characterization in detail using SEM/ EDX and XRD. In all samples, oxides of various morphologies developed on top of the Ni50Cr coatings. $\mathrm{Cr}_{2} \mathrm{O}_{3}$ was the main oxidation product on the surface of all three coatings. The coating with medium porosity and medium oxygen content has the best high-temperature oxidation performance in this study.
\end{abstract}

Keywords $\mathrm{Cr}_{2} \mathrm{O}_{3} \cdot \mathrm{HVOF} \cdot$ microstructure $\cdot \mathrm{Ni50Cr}$. $\mathrm{NiCr}_{2} \mathrm{O}_{4} \cdot$ oxidation $\cdot$ processing parameter

T. Hussain

tanvir.hussain@nottingham.ac.uk

1 Faculty of Engineering, The University of Nottingham, Nottingham NG7 2RD, UK

\section{Introduction}

High-chromium nickel-based alloys have been used successfully in oxidation resistance applications up to about $950{ }^{\circ} \mathrm{C}$ in industry (Ref 1 ) due to the formation of a dense and protective oxide scale at the surface. Recently, an increasing number of researchers investigated the potential for deposition of protective $\mathrm{NiCr}$ coatings onto power plant alloy substrates and the oxidation performance of deposited coating at various temperatures and in different environments (Ref 2-7). A potential route to deposit protective layers onto substrate for high-temperature oxidation/corrosion resistance in thermal power plant is thermal spray, especially HVOF thermal spray. Others such as weld-based techniques have certain limitations: high dilution of substrate elements into coatings, which comes from the excessive heat input during deposition time (Ref 8), excessive deposition time, etc. Thin-film deposition techniques such as physical/chemical vapor deposition (PVD/ CVD) are expensive, and the huge size of the boiler components is also a challenge for the processes (Ref 9). Typically, the powder particles in the liquid-fueled HVOF gas jet do not melt significantly to accelerate detrimental metallurgical changes in-flight. Therefore, excellent oxidation resistance of $\mathrm{NiCr}$ alloys can be retained through the HVOF thermal spray. Hence, most researches focused on the thermal spray as a suitable technique for high-temperature oxidation/corrosion protection for thermal power plants. For instance, Oksa et al. (Ref 3) carried out a longterm corrosion test of HVOF-sprayed NiCr16Mo, $\mathrm{NiCr} 9 \mathrm{Mo}$ and $\mathrm{NiCr} 10 \mathrm{Al}$ coatings in a biomass boiler environment and discovered that all those three coatings survived after the aggressive corrosion exposure. They also pointed out the preference of corrosion path within the coatings-oxidized lamellar boundaries and pores. Bluni 
and Marder (Ref 4) also obtained similar conclusion about the performance of HVOF-sprayed $\mathrm{NiCr}$ coating in coalfired combustion environment. On the other hand, according to the research of Uusitalo et al. (Ref 6), HVOF coatings contained high amounts of nickel and chromium failed to protect the substrates since the substrate was attacked by $\mathrm{Cl}$ and $\mathrm{S}$ in many cases. However, the best HVOF coatings in the study by Uusitalo et al. (Ref 6) were not penetrated by corrosive species and still provided suitable protection, i.e., HVOF thermal spray coating deposited with suitable process parameters can provide satisfactory protection to the substrate.

Oxidation resistance of HVOF coatings can be enhanced by adjusting processing parameters and thereby improving microstructure and properties of the deposited coating. According to the classification of Brandt (Ref 10), HVOF process parameters can be categorized into primary and secondary ones. The primary parameters contain the feedstock powder (composition, morphology, size and feed rate), the fuel gas (composition and flow rate), the oxygenfuel gas ratio, the carrier gas (composition, flow rate and pressure) and the gun design (nozzle type and dimensions). Effect of these parameters on properties of as-sprayed coating can be summarized as the effect of particle velocity and temperature, which are the most significant variables in determining the properties of a HVOF coating (Ref 11). According to prediction and experiment of Hackett (Ref 12), oxidation of particles in HVOF process is strongly affected by the fraction of particles molten upon impact, which is a function of particle temperature and velocity. Voggenreiter et al. (Ref 13) also obtained similar conclusion by adjusting particle temperature and velocity to an extent through varying the air-fuel ratio. Furthermore, particle temperature was identified as the key factor in oxidation of coating by Dobler et al. (Ref 14). Splat oxidation surprisingly decreased when the HVOF combustion mixture was oxygen rich, since this reduced the combustion temperature as well as the particle temperature. Unfortunately, they also pointed out that lowest particle temperature results in the poorest bond strength of the coating. Gu et al. (Ref 15) developed a numerical computational fluid dynamics (CFD) model of in-flight characteristics of Inconel 625 powder particles during a gasfueled HVOF thermal spray process, and they mostly focused on the effect of oxygen-fuel ratio and total mass flow rate on the profile of particle temperature and velocity. They concluded that the increment of particle velocity at low oxygen-fuel ratio is mainly due to the increase in total mass flow rate, since larger total mass flow rate brings about the greater density of fuel gas when fixed volume flow rates are considered.

In the present study, a gas atomized Ni50Cr feedstock powder was sprayed onto a power plant alloy using HVOF thermal spray using three processing parameters. The oxygen content and the porosity of the as-sprayed coatings were examined. Short-term and long-term high-temperature oxidation tests were conducted to investigate the oxidation behavior of the deposited coatings. SEM/EDX and XRD were used to identify the phase changes and oxidation products during the high-temperature oxidation. Experimental data included in this study (coating \#2) have been partly used in a previous publication that focused on the difference between a liquid-fueled HVOF thermal spray coating and a gas-fueled HVOF thermal spray coating (Ref 16).

\section{Experimental}

\section{Feedstock Powder and Substrate}

Gas atomized Ni50Cr powder (1260F/Ni-980-1) was sourced from Praxair surface technology Ltd. (Germany) and had a size range of $-53+20 \mu \mathrm{m}$. These powder particles were sprayed onto the substrate coupons that were machined from a $9 \mathrm{Cr}$ ferritic-martensitic boiler grade steel (ASME P92) pipe sections to size of $60 \times 20 \times 2 \mathrm{~mm}$. To improve substrate surface roughness and eliminate contaminants, respectively, these coupons were grit-blasted using brown alumina and degreased with isopropyl alcohol as the preparation procedure for spraying. Table 1 provides the compositions of the powder as well as the substrate. The composition of substrate was measured using atomic emission spectroscopy (AES) method.

\section{Deposition of Coating}

Met Jet IV HVOF system (Metallisation Limited, Dudley, $\mathrm{UK}$ ) was used to deposit the Ni50Cr powder onto the boiler steel substrate. In the MetJet III HVOF gun, kerosene and oxygen are fed into the combustion chamber in which kerosene is vaporized. The fuel vapor mixes with oxygen and the mixture burns before passing through the converging-diverging throat. The throat can accelerate the gas to a Mach number between 1.5 and 2 which passes through it (Ref 17). Two ports are located downstream of the throat to provide radial injection of the powder into gas stream. The gas and entrained powder then flow along the nozzle and become a free jet after leaving the nozzle (Ref 17). Flat

Table 1 Composition of feedstock powder and substrate (wt.\%)

\begin{tabular}{llllllll}
\hline & $\mathrm{Fe}$ & $\mathrm{Cr}$ & $\mathrm{Si}$ & $\mathrm{Ni}$ & $\mathrm{C}$ & $\mathrm{O}$ & Other \\
\hline Ni50Cr & 1 & 46 & 2 & Bal. & 0.1 & 0.027 & 1 \\
P92 & Bal. & 8.91 & 0.37 & 0.22 & 0.11 & & \\
\hline
\end{tabular}


coupons as mentioned above were mounted vertically on the circumference of a turntable with a vertical axis of rotation, and the spray gun was positioned at the front of the rotating coupons at a fixed standoff distance to give a horizontal spraying jet. Relative movement of coupons and spraying gun realizes continuous deposition of coating layers. This setup of the spraying apparatus has been reported in detail in previous publications (Ref 17).

Parameters as shown in Table 2 were selected according to a chart provided by the manufacturer of Metjet IV spraying system (Fig. 1) and previous studies. Figure 1 is plotted according to assumption of combustion reaction between oxygen and kerosene as shown in following formula.

$\mathrm{C}_{12} \mathrm{H}_{26}+18.5 \mathrm{O}_{2} \rightarrow 12 \mathrm{CO}_{2}+13 \mathrm{H}_{2} \mathrm{O}$

At the $100 \%$ stoichiometry, all input kerosene and oxygen were used, which was defined as complete combustion. That is to say, 1 mol of kerosene needs 18.5 mol of oxygen

Table 2 Three parameter combinations used in the Metjet IV thermal spray system

\begin{tabular}{|c|c|c|c|}
\hline Parameters & $\# 1$ & $\# 2$ & \#3 \\
\hline Oxygen flow rate, $1 \mathrm{~min}^{-1}$ & 900 & 878 & 920 \\
\hline Kerosene flow rate, $1 \mathrm{~min}^{-1}$ & 0.400 & 0.445 & 0.470 \\
\hline Oxygen stoichiometry, \% & 117 & 100 & 100 \\
\hline Total mass flow, $\mathrm{g} \mathrm{s}^{-1}$ & 26.5 & 26.5 & 28 \\
\hline Gun traverse speed, $\mathrm{mm} \mathrm{s}^{-1}$ & 5 & 5 & 5 \\
\hline Powder feed rate, $\mathrm{g} \mathrm{min}^{-1}$ & 72 & 72 & 72 \\
\hline Carrier gas flow rate, $1 \mathrm{~min}^{-1}$ & 6 & 6 & 6 \\
\hline Standoff distance, $\mathrm{mm}$ & 355 & 355 & 355 \\
\hline No of passes & 10 & 10 & 10 \\
\hline
\end{tabular}

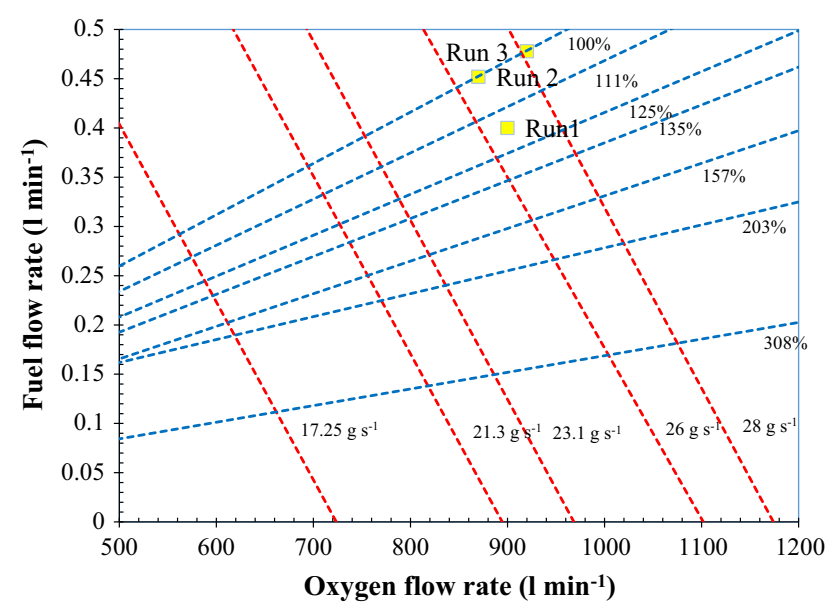

Fig. 1 A plot showing oxygen and kerosene flow rate for different total flow rate and percent stoichiometry illustrated selection of spraying conditions in Metjet IV spray setup (Red dash lines are total mass flow lines and Blue dash lines are stoichiometric lines) to complete combustion. Knowing mole volume of both kerosene and oxygen at certain temperature, the flow rate of oxygen and kerosene required for complete combustion can be calculated. The basic selection principle of the chart in Fig. 1 is as follows: moving across the stoichiometry lines, from a higher percentage to a lower percentage, leads to a decrease in the excess oxygen of the flame, resulting in an increase in flame temperature, and thus higher percentage of particle melting (Ref 18). The lowest oxygen-fuel ratio is the $100 \%$ line in the graph, and at all times the spraying is carried out at or above the $100 \%$ stoichiometric conditions (i.e., always at or $>100 \%$ line). This is because values lower than the $100 \%$ line result in unburnt kerosene in the flame and potential contamination in the coating. Moving across the total mass flow rate lines from low to high also has an effect on the flame temperature but to a lesser extent according to Gu et al. (Ref 15).

\section{High-Temperature Air Exposure of as-Sprayed Coatings}

The oxidation kinetics of coatings deposited in various parameter conditions was obtained using a thermogravimetric analyzer (TGA) (TA instruments Q600, Herts, UK). Freestanding coatings were produced by spraying onto ground substrates of reduced roughness, which then were carefully shaped around a mandrel to delaminate the coatings from the substrate. Freestanding coatings were sliced into a square section of dimensions approximately $3 \times 3 \times 0.2 \mathrm{~mm}$ due to the size limitation of TGA crucibles (Ø $5.5 \mathrm{~mm}$ and height $4 \mathrm{~mm}$ ) using a precision diamond tipped cutting disk. The top surface, which is of interest, has an area of $9 \mathrm{~mm}^{2}$, which only occupies $44 \%$ of the total surface area $\left(20.4 \mathrm{~mm}^{2}\right)$, while the mass gain comes from all six sides (100\%) - taking no account of the internal oxide. The four sides of freestanding samples only occupy $12 \%$ of the total surface area, and the bottom surface of freestanding samples occupies $44 \%$ of the total surface area. One point should be noted that the bottom surfaces of three coatings have similar surface roughness because they were deposited on substrates with identical surface preparation and the sides were manufactured under identical surface preparations. The total mass gain from the TGA was divided by all six surfaces to calculate specific mass change data. This is a standard practice in hightemperature oxidation of coatings as the main differences among various TGA curves are mainly due to the coating microstructures. Irrespective of the small error involved due to sample preparation techniques, the method still provides reasonably accurate information about oxidation performance of the freestanding samples. To ensure the accuracy of TGA test, those samples then were cleaned using industrial methylated spirit and dried in an oven as a 
preparation procedure. After cleaning, the specimens held in recrystallized alumina pans were heated at a rate of $5{ }^{\circ} \mathrm{C} \mathrm{min}{ }^{-1}$ to the test temperature of $700{ }^{\circ} \mathrm{C}$ in commercial grade bottled air (flow rate of $20 \mathrm{~mL} \mathrm{~min}^{-1}$ ). The test temperature was maintained for $4 \mathrm{~h}$ to obtain the weight change data. The samples were cooled to room temperature at a rate of $5{ }^{\circ} \mathrm{C} \min ^{-1}$. Considering the weight change data before the sample reached the target test temperature, the TGA data were corrected before plotting.

The long-term air heat treatment at $700{ }^{\circ} \mathrm{C}$ was conducted in a box furnace (Lenton ECF 12/6, Lenton Thermal Design Ltd., UK) with continuous air ventilation for 1,10 and $100 \mathrm{~h}$ with a heating and cooling rate of $5{ }^{\circ} \mathrm{C} \mathrm{min}^{-1}$. The specimens used in the long-term oxidation exposure were coated substrates that were placed in individual crucibles made from high-purity alumina.

\section{Characterization of As-Sprayed and Exposure Coatings}

To observe the top morphology of feedstock powder, coatings after spraying and after oxidation tests the specimens were placed onto carbon stubs and examined using SEM. To analyze cross sections of those specimens, powder particles and cross-sectioned as-sprayed coatings were mounted in a conductive resin, ground and polished to a $0.6 \mu \mathrm{m}$ colloidal silica finish for the SEM examination. The as-sprayed coatings were cut using a diamond tipped precision cutting saw. To prevent spallation and breakdown of oxide scale, coatings after air oxidation were coldmounted immediately with a low shrinkage resin filled with glass bids without any cutting before grinding and polishing. All microstructure investigations were performed in an FEI field emission gun SEM (FEI, Eindhoven, Netherland) at $20 \mathrm{kV}$. The morphology of powder and coatings was examined in the SEM using secondary electron (SE) signal, while the cross section of the samples was examined using backscattered electron (BSE) signals. The EDX analysis was also performed to characterize the oxides and analyze the composition of the coatings.

To identify the phase composition of powder, as-sprayed and heat-treated coatings, XRD was performed using a Siemens D500 diffractometer employing monochromatic $\mathrm{Cu} \mathrm{K} \alpha$ with a wavelength of $0.15406 \mathrm{~nm}$ radiation. Scanning parameters were set between 20 and $90^{\circ}$ with a $2 \theta$ step size of $0.05^{\circ}$ and a dwell time per step of $5 \mathrm{~s}$.

LECO oxygen analyzer (LECO ON736, LECO Instruments UK Ltd., Stockport, UK) was used to determine the content of oxygen in as-sprayed coatings. The carbon element in the pure graphite crucibles, which hold the test specimens, is oxidized by the oxygen from the test specimens, while the total system is heated under a flowing stream of inert gas (usually helium). The infrared absorption and thermal conductivity of gases including $\mathrm{CO}_{2}$ are measured. The content of oxygen in the specimens can be evaluated by knowing the weight of $\mathrm{CO}_{2}$ and the specimen. For each coating, the LECO oxygen analysis was repeated three times to obtain an average value.

Mercury cannot wet most substances and cannot spontaneously penetrate pores by capillary action; it must be forced into the pores with the application of external pressure. The required equilibrated pressure is inversely proportional to the size of the pores. Mercury intrusion porosimeter (MIP) uses this phenomenon to measure the porosity of as-sprayed coating. The machine used in this study is AutoPore IV 9500 (Micrometrics, Micrometrics UK Ltd., Hexton, UK). Freestanding deposits were used in the MIP tests to measure the inter-connected porosity.

\section{Results}

\section{Microstructure and Phase of Powder and As-Sprayed Coatings}

XRD patterns of the Ni50Cr feedstock powder and three as-sprayed coatings are shown in Fig. 2. Three main peaks of the powder XRD pattern $\left(2 \theta=43.5^{\circ}, 51^{\circ}\right.$, and $\left.76^{\circ}\right)$ correspond to the fcc $\gamma-(\mathrm{Ni}, \mathrm{Cr})$ solid solution phase, and three minor peaks $\left(2 \theta=45^{\circ}, 65.5^{\circ}\right.$, and $\left.83^{\circ}\right)$ corresponds to the bcc $\alpha$-Cr phase. Slight left shift of the position of these main peaks compared to that of pure fcc $\mathrm{Ni}$ phase peaks was observed in the diagram. This shift is due to the expansion effect of the $\mathrm{Cr}$ atom in the lattice of $\mathrm{Ni}$, which is due to the rapid cooling of $(\mathrm{Ni}, \mathrm{Cr})$ super-saturated solution during the feedstock powder manufacturing in the gas atomization process. There was no oxide phase, or at least the weight fractions of any oxides phases were below the detection limit in the XRD pattern for feedstock powder. The morphology of the as-received powder particles is shown in Fig. 3(a). Most powder particles are of nearspherical geometry since they are manufactured using inert gas atomization method (Ref 19). It also reveals that there are some smaller satellite particles around larger particles. The polished cross-sectional image of a power particle shows a dendritic solidification pattern as a consequence of gas atomization (Fig. 3b).

For the XRD patterns of three as-sprayed coatings, there is no obvious difference between them. As-sprayed coatings retained the main fcc $\gamma-(\mathrm{Ni}, \mathrm{Cr})$ solid solution phase. The corresponding peaks broaden due to the lattice distortion occurred during the spray process (Ref 20). The two minor $\alpha$-Cr peaks $\left(2 \theta=65.5^{\circ}\right.$ and $\left.83^{\circ}\right)$ were not clearly identified in the three as-sprayed coating. It should be 
Fig. 2 XRD patterns of asreceived feedstock powder and three as-sprayed coatings

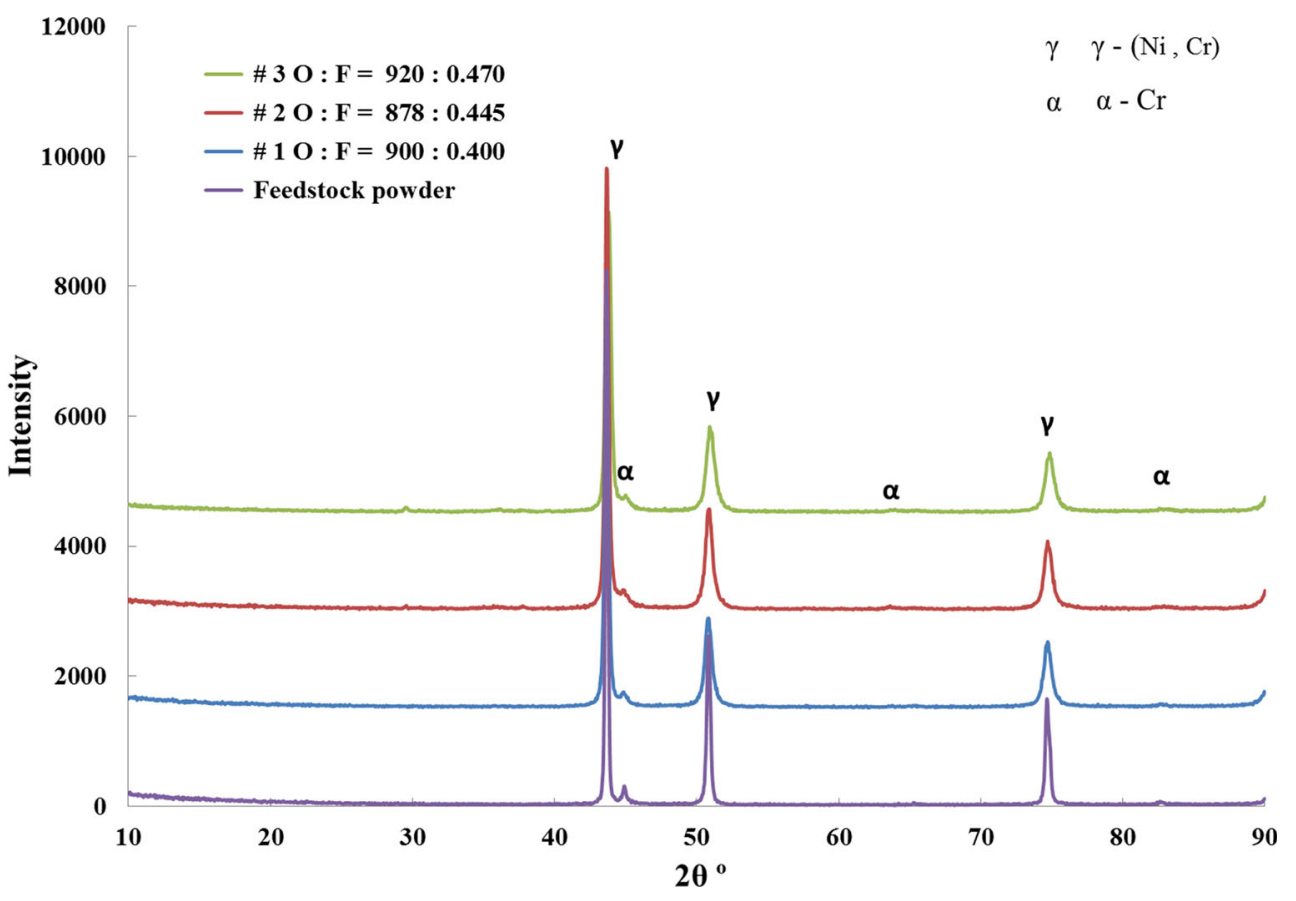

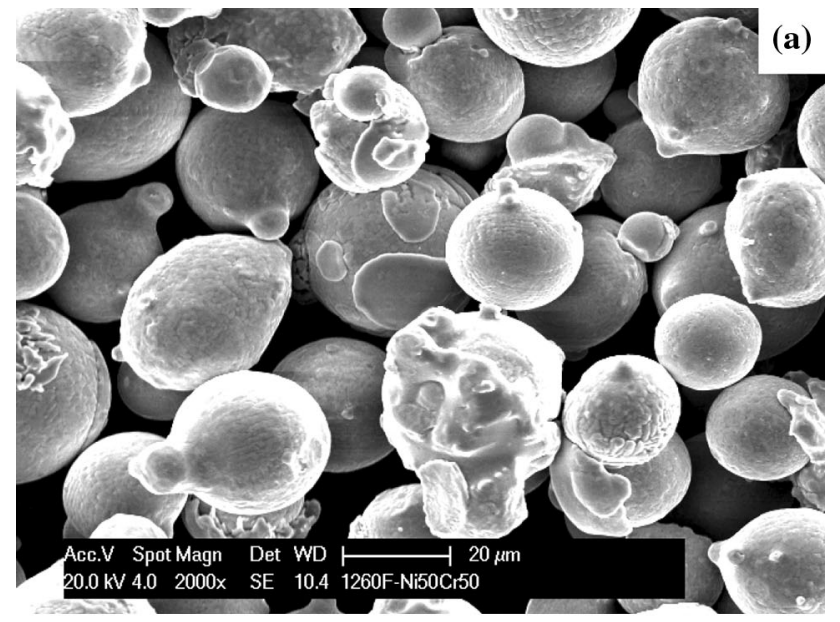

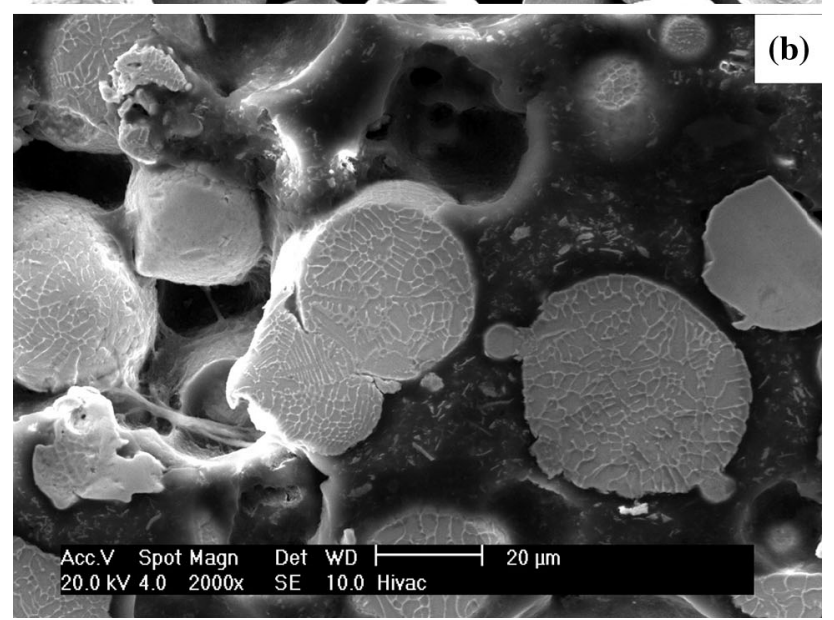

Fig. 3 SEM images of (a) as-received powder particles morphology; (b) polished cross section noted that no oxide peaks were detected in the XRD patterns of the as-sprayed coatings within the detection limit of the XRD (1-2 wt.\%) (Ref 17).

Figure 4 shows the BSE images of the cross section of all three coatings on P92 substrates. All three images show a typical lamellar thermal spray microstructure. There is no delamination and crack between coating and substrate in any coating. The thicknesses of as-sprayed coating are all around $250 \mu \mathrm{m}$, and only in coating \#1 a top porous layer ( $\sim 50 \mu \mathrm{m})$ was detected. The porosity present at the top layer of the coating has been reported in previous investigations during high velocity impact, including cold spraying, due to a lack of deformation of the splats in the absence of a hammering action by subsequent particle impact (Ref 21). Particles which are not sufficiently molten or traveling at lower velocities are likely to result in imperfect bonding and porosity consequently. The porosity is most obvious in coating \#1 as can be seen from Fig. 4(a). Gray pixels in the BSE images around the splats (powder particles with deformation of different extent) which are darker in images indicate presence of thin oxide layer (Ref 22 ), which was also confirmed by the EDX analysis. It is noticeable from Fig. 4 that there is less oxide surrounding the splats in coating \#1 when comparing coating \#1 with coatings \#2 and \#3. This phenomenon is also confirmed by the LECO infrared oxygen contents analysis of freestanding coatings. There is $0.257 \mathrm{wt} . \%$ oxygen in coating \#1, 0.464 wt. $\%$ oxygen in coating \#2 and 0.944 wt.\% in coating \#3. Higher-magnification images of cross section of three coatings are shown in Fig. 5. For coating \#1, pores and gaps between splats (thin black area surrounding the 

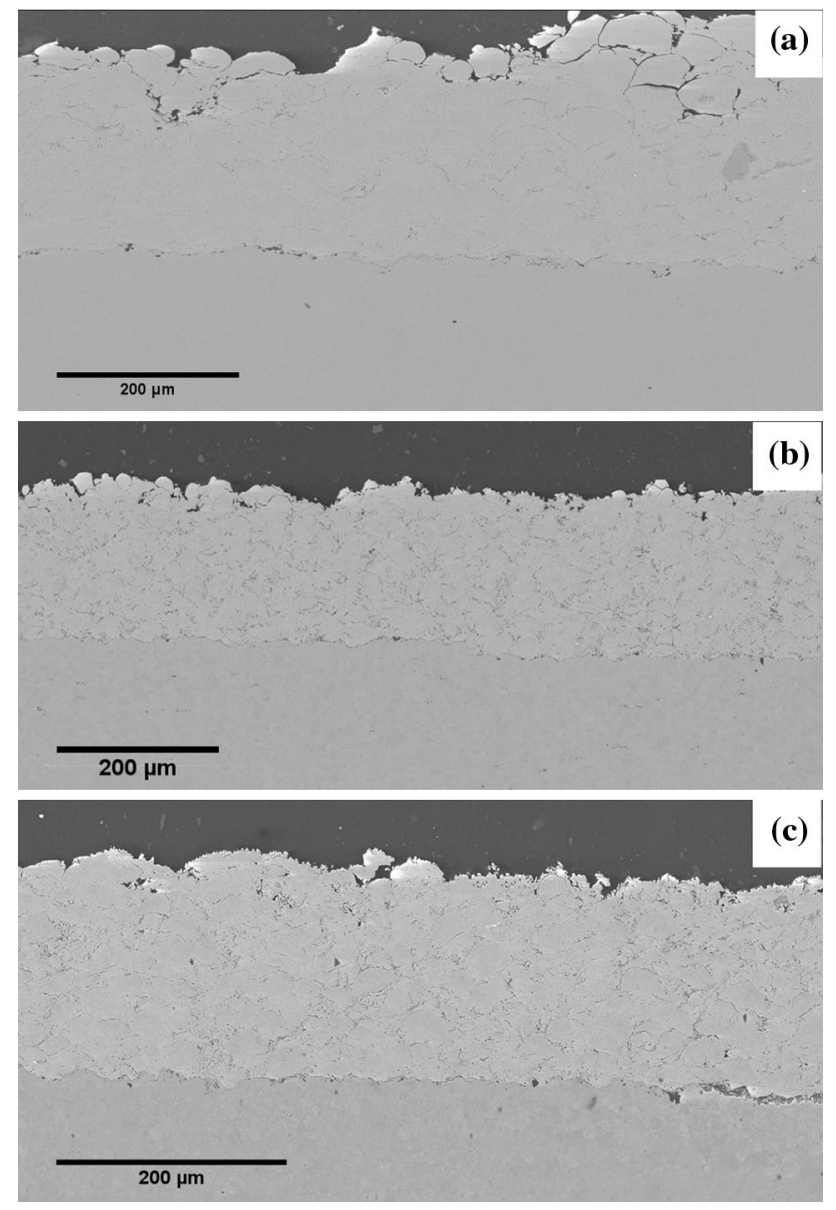

Fig. 4 SEM images of the cross section of coatings: (a) coating \#1 (900: 0.400); (b) coating \#2 (878: 0.445); (c) coating \#3 (920: 0.470)

splats) can be observed from Fig. 5(a). Microstructures of coatings \#2 and \#3 were better than that of coating \#1 since there was almost no gap and pore between splats. Based on the fact, there were more gray pixels inside Fig. 5(b) and (c) than that in Fig. 5(a), i.e., coatings \#2 and coating \#3 experienced more intense oxidation during spraying. This observation was consistent with LECO oxygen content analysis results.

Top morphology of the as-sprayed coating is displayed in Fig. 6. There is a large amount of unmelted and/or semimolten particles on the surface, which has hemispherical morphology. This is representative of the coatings morphology typically observed in the liquid-fueled HVOF spray, where the particles are not fully molten due to the low flame temperature of kerosene and short dwell time at high temperature. According to Fig. 6, there are more unmelted particles on the surface of coating \#1 than that on the surface of coatings \#2 and \#3, indicating that powder particles during \#2 and 3 thermal spray were sufficiently heated and thereby experienced more significant deformation and splat formation.
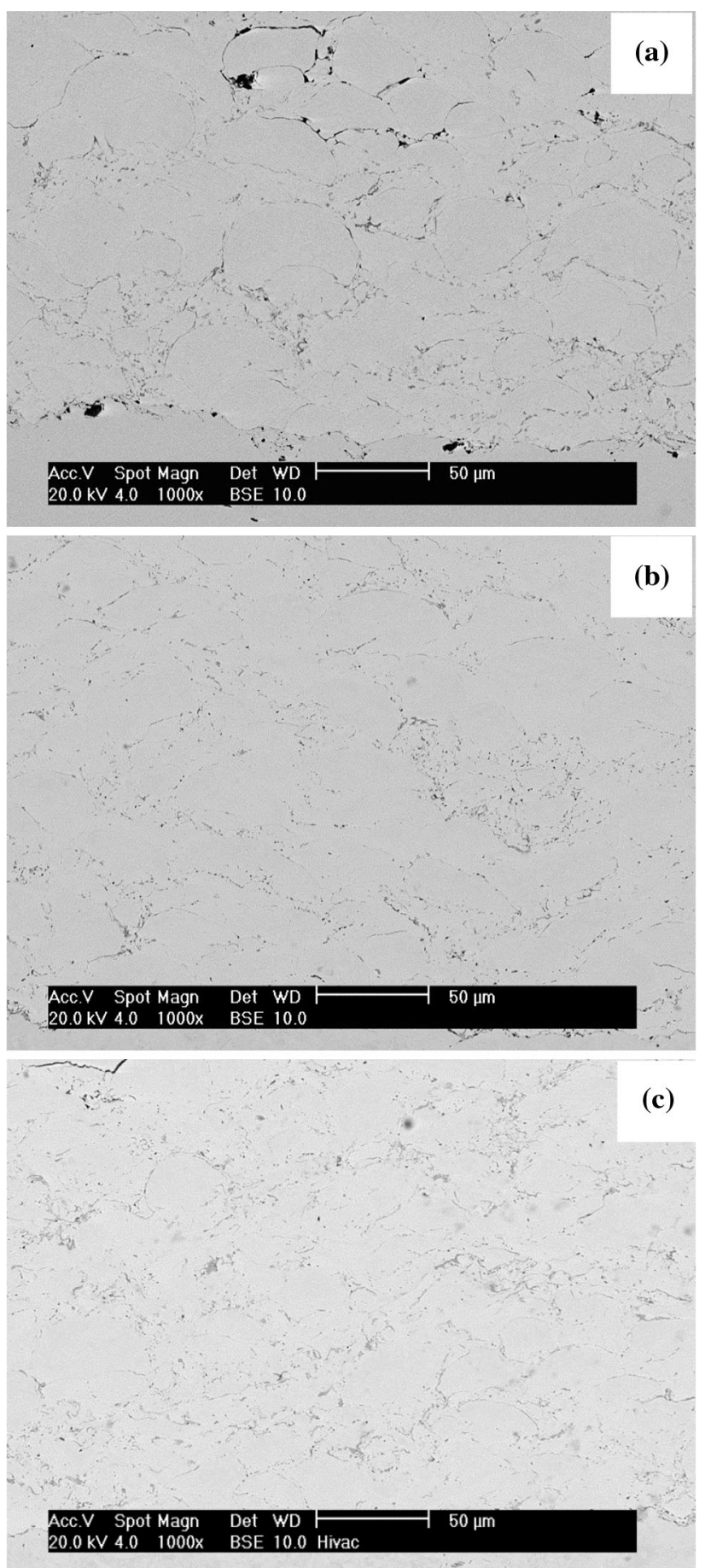

Fig. 5 SEM images of cross section of coatings at high magnification: (a) coating \#1 (900: 0.400); (b) coating \#2 (878: 0.445); (c) coating \#3 (920:0.470)

\section{Porosity of As-Sprayed Coatings}

MIP is the most accurate method to provide information about the size distribution of pores and volume percentage of open inter-connected porosity. This information is useful in evaluating oxidation performance of coatings since 

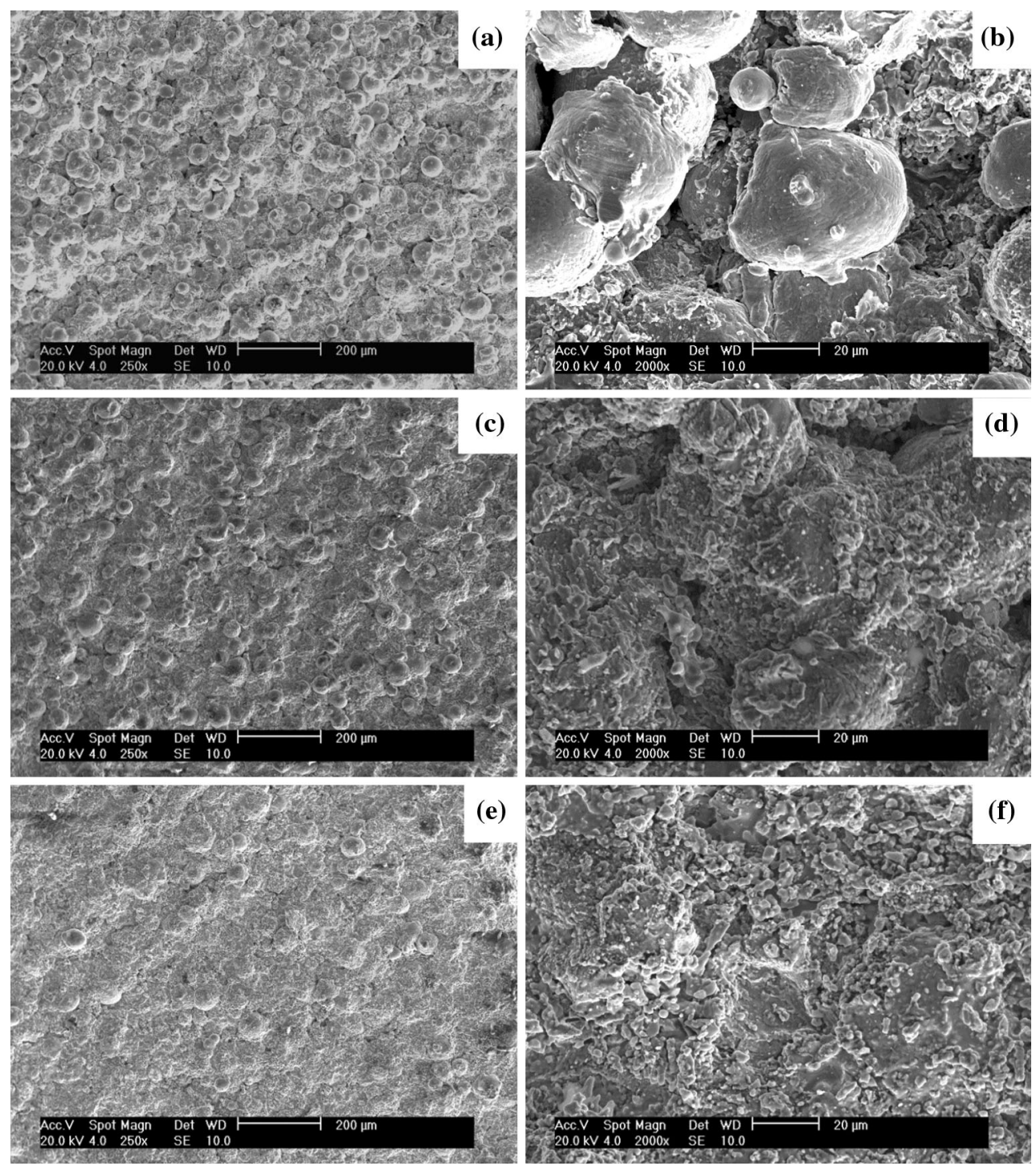

Fig. 6 SEM images of top morphology of coatings: (a, b) coating \#1 (900: 0.400); (c, d) coating \#2 (878: 0.445); (e, f) coating \#3 (920: 0.470)

pores inside the HVOF coatings are the main transport path of oxygen ion (Ref 22). Diffusion of oxygen ions and other corrosive species is much faster in pores than in metal and oxide scale (Ref 4). The incremental intrusion of mercury versus pore sizes in all three as-sprayed coatings is plotted in Fig. 7(a). The size distribution of pores inside the coating \#1 was concentrated at 8-13 $\mu \mathrm{m}$ and $13-20 \mu \mathrm{m}$. The size distribution of pores inside the coating \#2 falls in two distinctive ranges, i.e., one distribution between 0.06 and $0.3 \mu \mathrm{m}$ and another distribution between 8 and $20 \mu \mathrm{m}$. For coating \#3, the size distribution of most pores was 8-20 $\mu \mathrm{m}$. Figure 7(b) shows the cumulative intrusion of mercury versus pore sizes for all coatings. Coating \#1 had the largest cumulative intrusion $\left(0.0059 \mathrm{~mL} \mathrm{~g}^{-1}\right)$, which is nearly double of that of coating \#2 $\left(0.0028 \mathrm{~mL} \mathrm{~g}^{-1}\right)$ and \#3 $\left(0.0019 \mathrm{~mL} \mathrm{~g}^{-1}\right)$. There is minor difference in cumulative porosity between coatings \#2 and \#3. Ignoring the oxides in the coating and knowing the density of the feedstock material, the cumulative intrusion of mercury can be converted to the volume percentage of porosity using following equation.

$\%$ porosity $=\frac{V_{\mathrm{Hg}(\text { cumulative intrusion })}}{V_{\text {bulk }}} \times 100$

where $V_{\mathrm{Hg}}$ is cumulative volume of mercury intrusion and $V_{\text {bulk }}$ is bulk volume of the sample which can be determined from density and mass of the sample. One point needs to be noted is the density of sample is estimated using the density of the feedstock powder to simplify the measurement process. Taking the density of the feedstock powder as $8.2 \mathrm{~g} \mathrm{~cm}^{-3}$, the porosity of the coatings was: 4.83 vol.\% in coating \#1, $2.30 \mathrm{vol} . \%$ in coating \#2 and 1.59 vol.\% in coating \#3 respectively. 

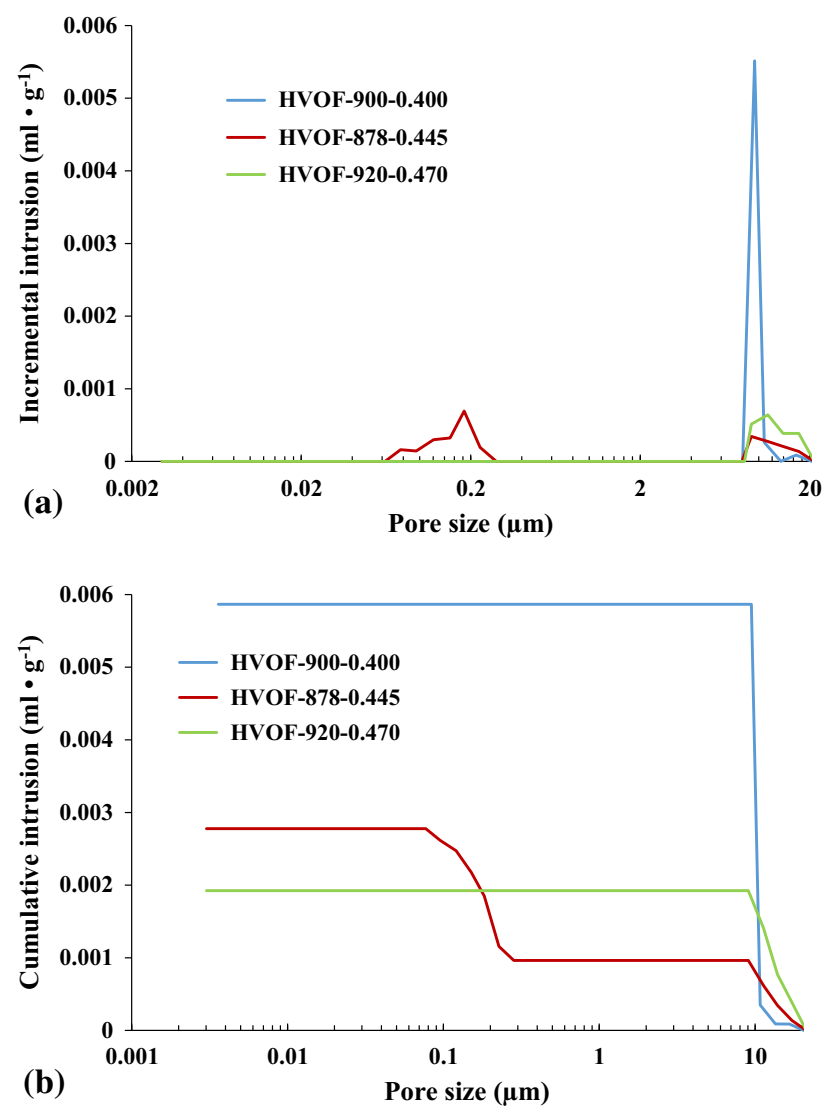

Fig. 7 Incremental (a) and cumulative (b) intrusion of mercury vs. pore size of freestanding coatings

\section{High-Temperature Oxidation}

\section{Oxidation Kinetics Obtained Using TGA}

The TGA results of three freestanding coatings for $4 \mathrm{~h}$ at $700{ }^{\circ} \mathrm{C}$ are shown in Fig. 8(a). Mass gain of the coating \#1 was about $0.534 \mathrm{mg} \mathrm{cm}^{-2}$ after $4 \mathrm{~h}$, while the mass gain of the coating \#3 was $0.337 \mathrm{mg} \mathrm{cm}^{-2}$ and the mass gain of the coating \#2 was $0.2695 \mathrm{mg} \mathrm{cm}^{-2}$. To determine the kinetics of oxidation of three coatings, the square of the specific mass change versus time is plotted in Fig. 8(b). The data suggests that the slopes of all curves begin to reduce at around $60 \mathrm{~min}$, thus two straight lines can be fitted in each TGA curve to describe a two-stage oxidation phenomena (before and after $60 \mathrm{~min}$ ). For coating \#1, the gradient of the straight line at the first stage is $1.6 \times 10^{-3} \mathrm{mg}^{2} \mathrm{~cm}^{-4} \mathrm{~min}^{-1}$, which reduces to $1.1 \times 10^{-3} \mathrm{mg}^{2} \mathrm{~cm}^{-4} \mathrm{~min}^{-1}$ at the following stage. For coating \#2, the gradient of the corresponding straight line for first stage is $6 \times 10^{-4} \mathrm{mg}^{2} \mathrm{~cm}^{-4} \mathrm{~min}^{-1}$ which decreases to $2 \times 10^{-4} \mathrm{mg}^{2} \mathrm{~cm}^{-4} \mathrm{~min}^{-1}$ after $60 \mathrm{~min}$. Finally, the gradients of the straight lines for coating \#3 are $7 \times 10^{-4}$ and $4 \times 10^{-4} \mathrm{mg}^{2} \mathrm{~cm}^{-4} \mathrm{~min}^{-1}$, respectively. A similar methodology to calculate rate constants in
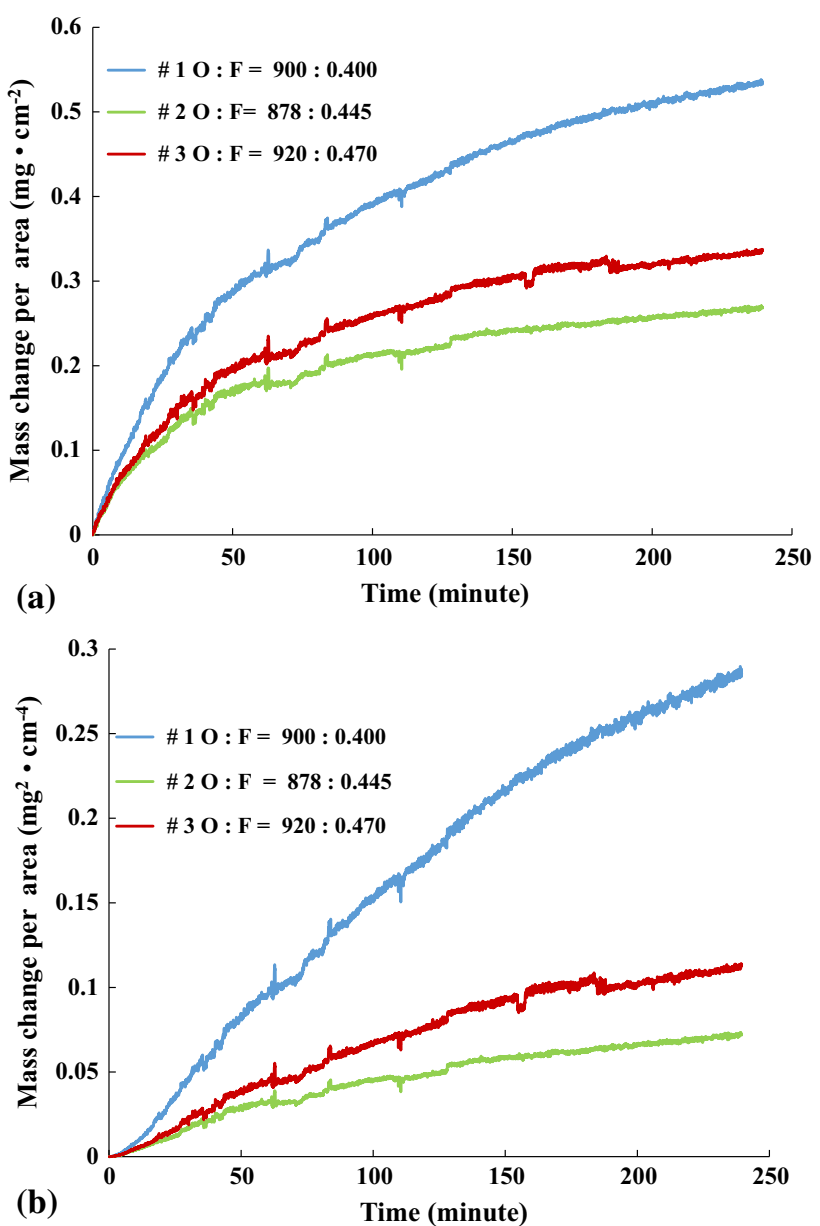

Fig. 8 (a) TGA curves of three freestanding coatings; (b) square of the specific mass change vs. time curves of all three coatings

thermally sprayed Ni50Cr coatings was reported in literature (Ref 16). In all three samples, the $R$-squared value for all the straight lines was between 0.93 and 0.98 .

\section{Oxidation Products, Morphology and Cross Section}

To investigate the oxides evolution with time at the surface of coating, SE images of the top morphology of the oxide grains identified as $\mathrm{Cr}_{2} \mathrm{O}_{3}$ according to the XRD results for coating \#1 after 1,10 and $100 \mathrm{~h}$ are provided in Fig. 9. Coverage of the oxides on the surface of the coating appeared after $1 \mathrm{~h}$ heat treatment, and the oxides developed to a homogenous coverage with uniform geometry with time. After $1 \mathrm{~h}$, most oxides were in thin flake geometry. Those oxide flakes thickened after $10 \mathrm{~h}$ of exposure. This trend of increasing size continued up to $100 \mathrm{~h}$. At last, the oxides have transformed into large oxide grains of around $2 \mu \mathrm{m}$ size. In addition, there were some hexagonal grains nearby the thin oxide grains as shown in Fig. 9(c).

XRD patterns of coating \#1 as-sprayed and after 1, 10 and $100 \mathrm{~h}$ heat treatment are plotted in Fig. 10(a). There is 

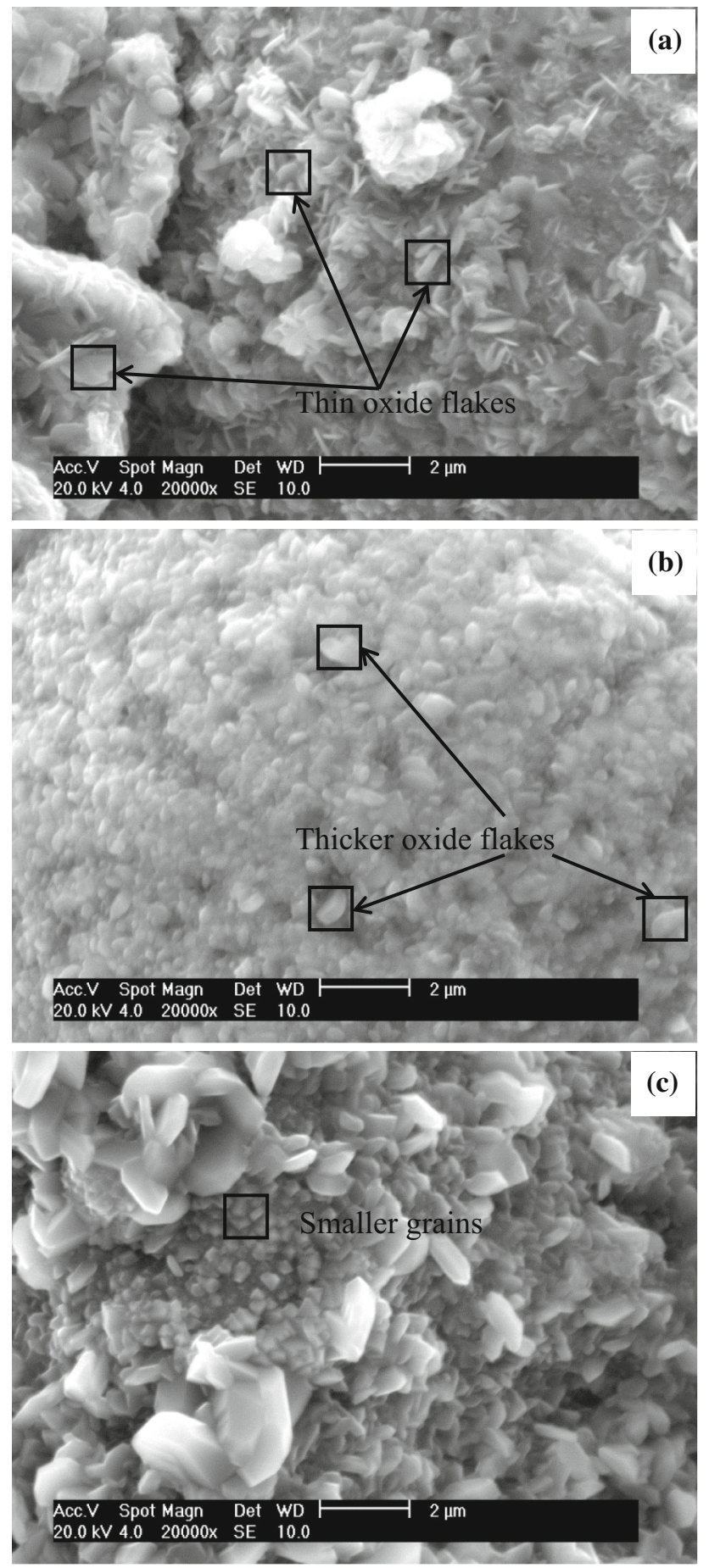

Fig. 9 Top morphology of coating \#1:900:0.400 after 1, 10 and $100 \mathrm{~h}$ exposure: (a) $1 \mathrm{~h}$; (b) $10 \mathrm{~h}$; (c) $100 \mathrm{~h}$

no obvious change regarding the metallic phases with increasing exposure time. The main oxide phase is $\mathrm{Cr}_{2} \mathrm{O}_{3}$, and its amount steadily increased since the intensity of original oxide peaks went up.

XRD patterns of the oxidation products after high-temperature air exposure for $100 \mathrm{~h}$ of three coatings are shown in Fig. 10(b). To provide a reference, XRD pattern of feedstock powder after $100 \mathrm{~h}$ heat treatment under same condition was also shown. For coating \#1 and coating \#3, $\mathrm{Cr}_{2} \mathrm{O}_{3}$ is the only oxide identified within the detection limit of XRD. The minor $\alpha-\mathrm{Cr}$ peaks near the major $\gamma$ phase $(\mathrm{Ni}$, Cr) peaks $\left(2 \theta=45^{\circ}\right)$ increased in relative intensity and sharpened after $100 \mathrm{~h}$ high-temperature oxidation. While for coating \#2, no $\alpha$-Cr peak was detected. In addition to $\mathrm{Cr}_{2} \mathrm{O}_{3}$ peaks, $\mathrm{NiO}$ and $\mathrm{NiCr}_{2} \mathrm{O}_{4}$ oxides were also detected in coating \#2. The evolution of metallic phase of the feedstock powder was similar to that of coatings \#1 and \#3. The main oxide phase of the powder was $\mathrm{Cr}_{2} \mathrm{O}_{3}$.

Oxide grains morphology after $100 \mathrm{~h}$ heat treatment of coatings \#2 and \#3 and feedstock powder was examined, and the SE images are presented in Fig. 11. It appears that except the oxides on the surface of coating \#1 (Fig. 9c), most oxides on the surface of coatings \#2 and \#3 have uniform size and geometry. Oxides on the surface of coating \#1 is a mixture of hexagonal and flake type grains. The oxide on the surface of coating \#2 is mostly hexagonal and has the largest size distribution. While for coating \#3, oxide grains on its surface are finer than that on the surface of coating \#2 and the geometry is mostly hexagonal. No flake type grains were observed on the top surface of oxidized powder according to Fig. 11(c). The hexagonal grains on the powder particles had a size distribution between 0.5 and $2 \mu \mathrm{m}$.

BSE images of the cross section of all three coatings after $100 \mathrm{~h}$ high-temperature oxidation are shown in Fig. 12. According to the images, the oxide scales on the top surface of all three coatings are relatively thin. The pores near the top surface of coating \#1 (indicated by white rectangles in Fig. 12a) show oxidation of splats. This process does not occur in coatings \#2 and \#3. The oxides on the top surface of coating \#3 formed an accumulation of oxide grains rather than a dense oxide scale, which can act as a precursor of oxidation barrier, as indicated in Fig. 12(c).

The pre-existing oxides in the as-sprayed coatings also thickened with the exposure time, as shown in Fig. 12(b) with an arrow. EDX spectrum 1 showed that these oxides are mostly chromia with silicon and minor amount of nickel. The bulk coating microstructure following the heat treatment presents a dual phase microstructure. The darker phase inside the splats (in BSE images) contains around $60-80 \mathrm{wt} . \%$ chromium, while the lighter phase includes about 50-60 wt.\% nickel. This twophase microstructure can be observed in all three coatings according to Fig. 12. It seems that the dual phase phenomenon inside the splats has a preferential orientation in the coating \#1 (Fig. 12a). For instance, the splat indicated by arrows shows that the dual phase structure appeared on the lower section, since the top section had more scope to react with the air infiltrated through pores. 
Fig. 10 (a) XRD patterns of assprayed coating \#1 (900:0.400) and after 1,10 and $100 \mathrm{~h}$ oxidation exposure; (b) XRD patters of powder, coating \#1 (900:0.400), coating \#2 (878:0.445) and coating \#3 (920:0.470) after $100 \mathrm{~h}$ of oxidation exposure

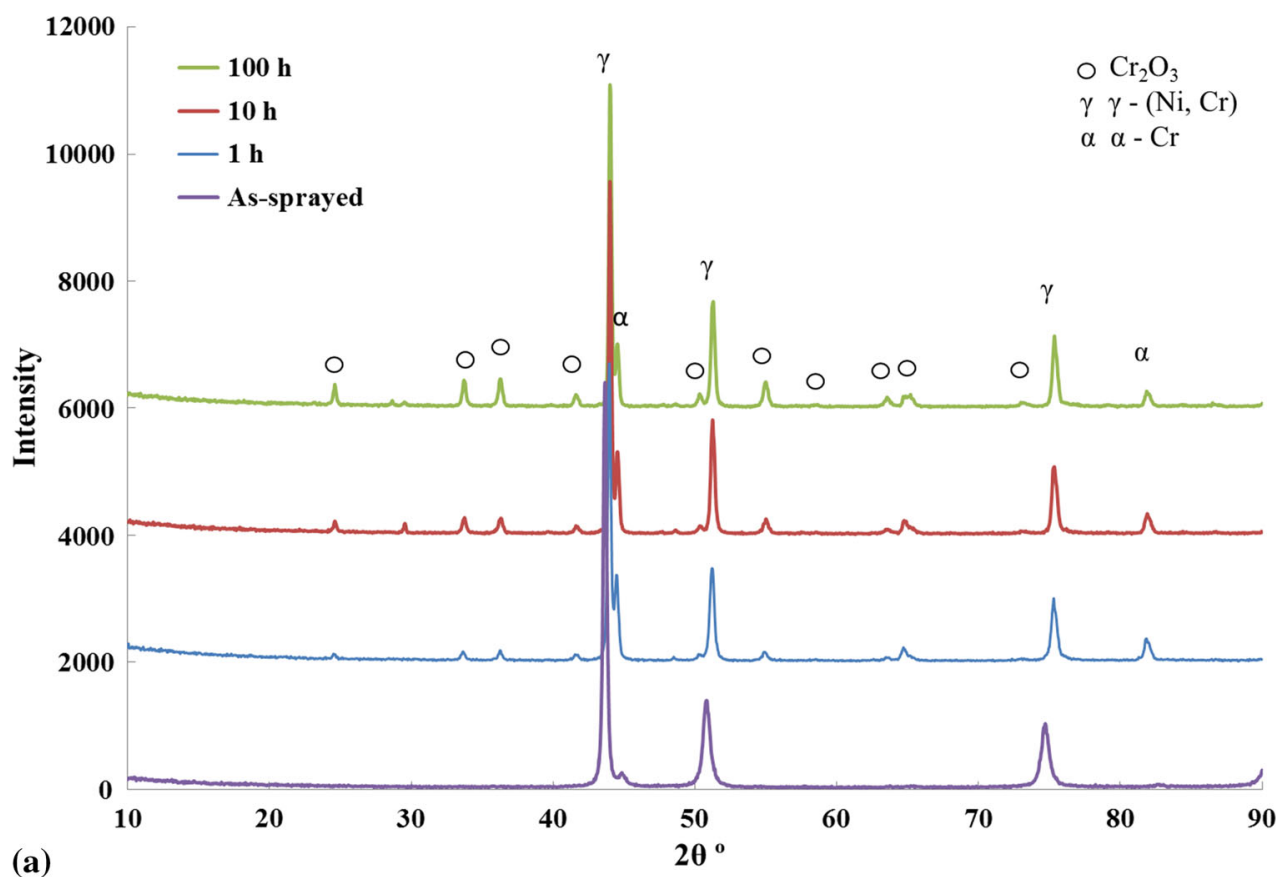

(a)

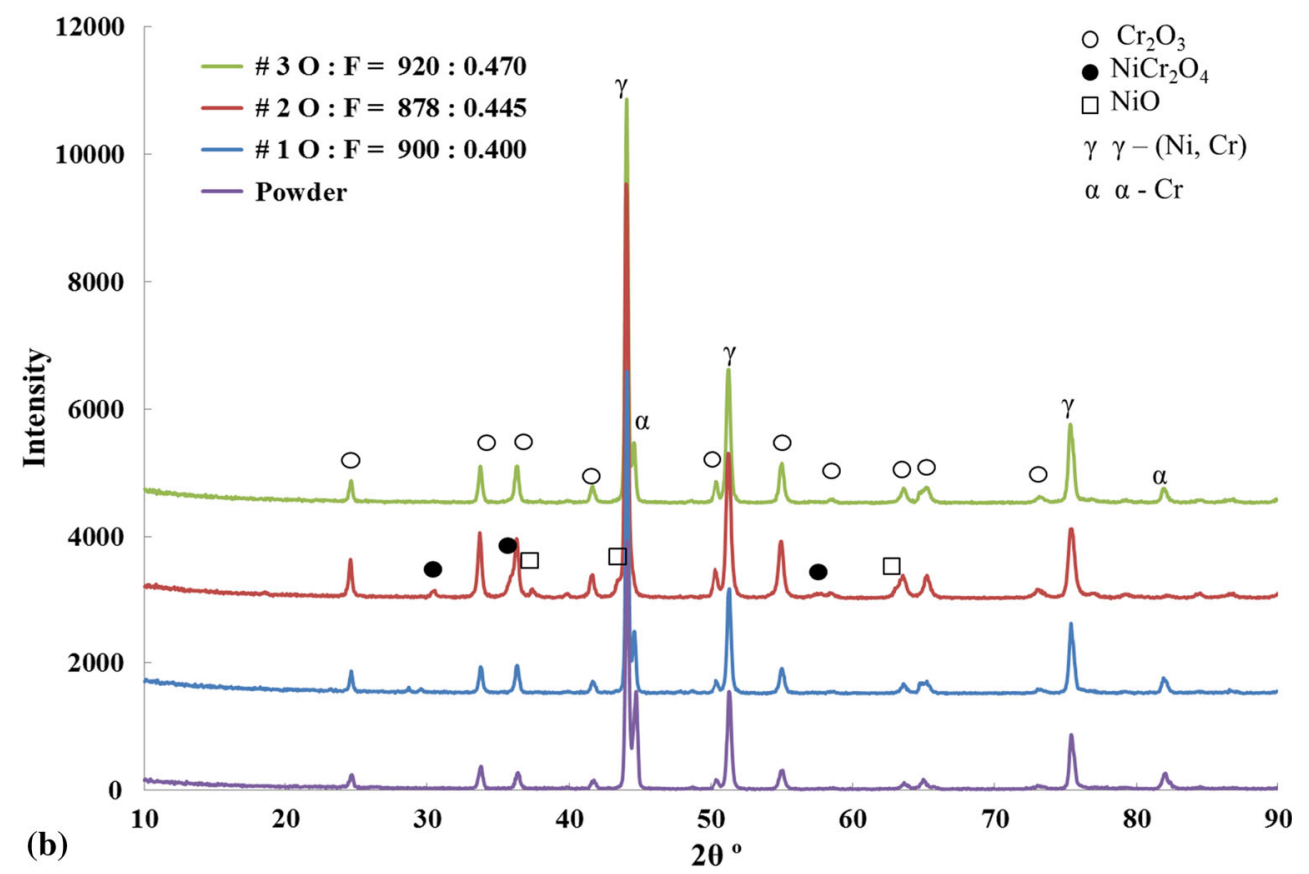

\section{Discussion}

\section{Effect of Processing Parameters on Microstructure and Porosity of the Coatings}

By altering the oxygen to fuel stoichiometry, it is possible to change the temperature and exit velocity of the gas, temperature and momentum of the particles as they impact onto the substrate which in turn affects the porosity and the bonding of the particles (Ref 23). This explains the difference in microstructure and porosity between coating \#1 and coating \#2, where coating \#1 was sprayed at higher oxygen-fuel ratio (excess oxygen in the flame). Oxygen stoichiometry of coating \#2 is $\sim 100 \%$, lower than that of coating \#1. There is no excess oxygen for the combustion of kerosene during spraying of coating \#2 which also results in higher exit gas velocity (Ref 24). Wanphut (Ref 24) performed a particle image velocimetry (PIV) study with DPV 2000 on thermal spray of MCrAlY powder, and it was reported that the average particle temperature 

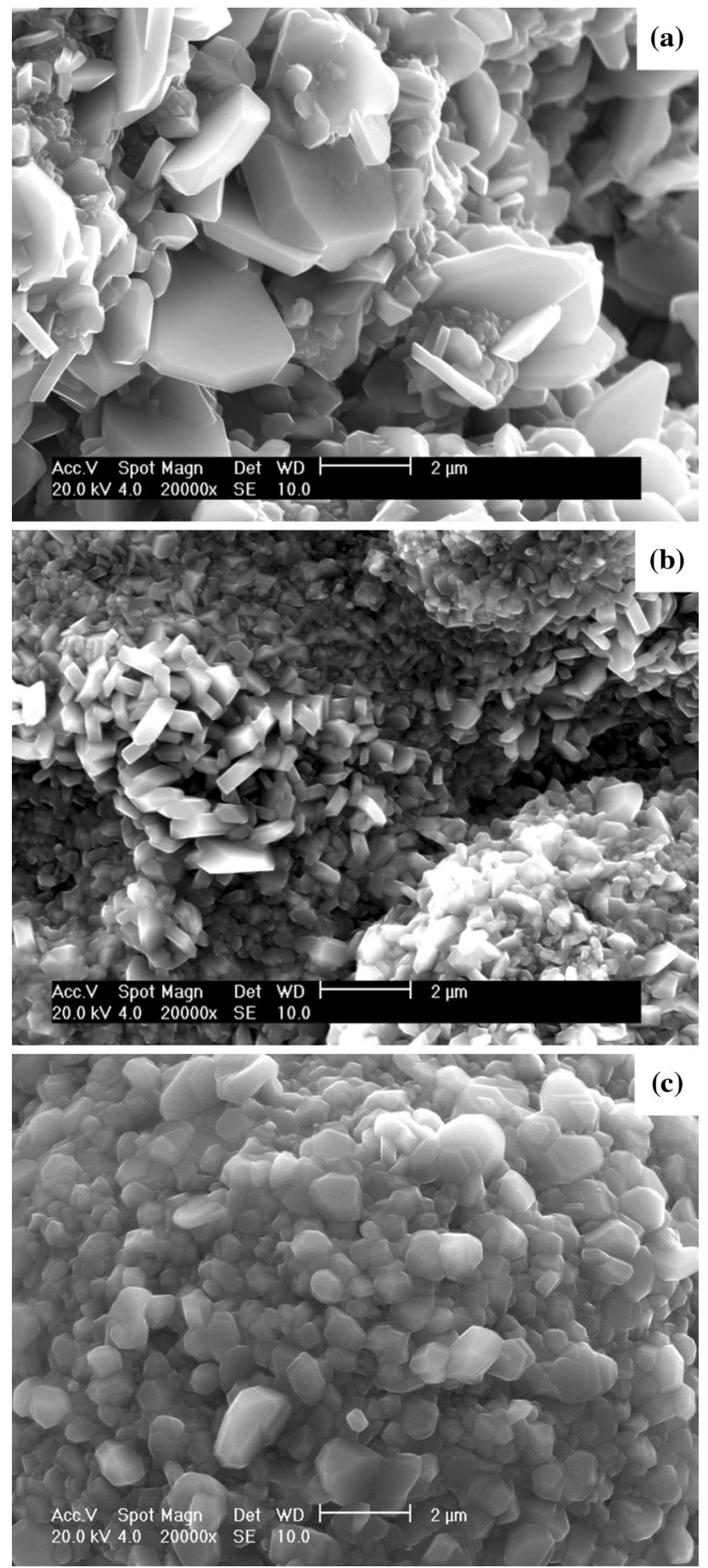

Fig. 11 Top morphology of (a) coating \#2 (878:0.445) (b) coating \#3 (920: 0.470) and (c) powder after $100 \mathrm{~h}$ exposure

increases and the average particle velocity decreases as the oxygen stoichiometry decreases. The particles in coating \#2 are largely deformed due to the higher impact velocities compared to coating \#1. In the oxygen stoichiometry above $100 \%$, an oxygen-rich mixture is created due to excess oxygen molecules in the flame. Such a condition could
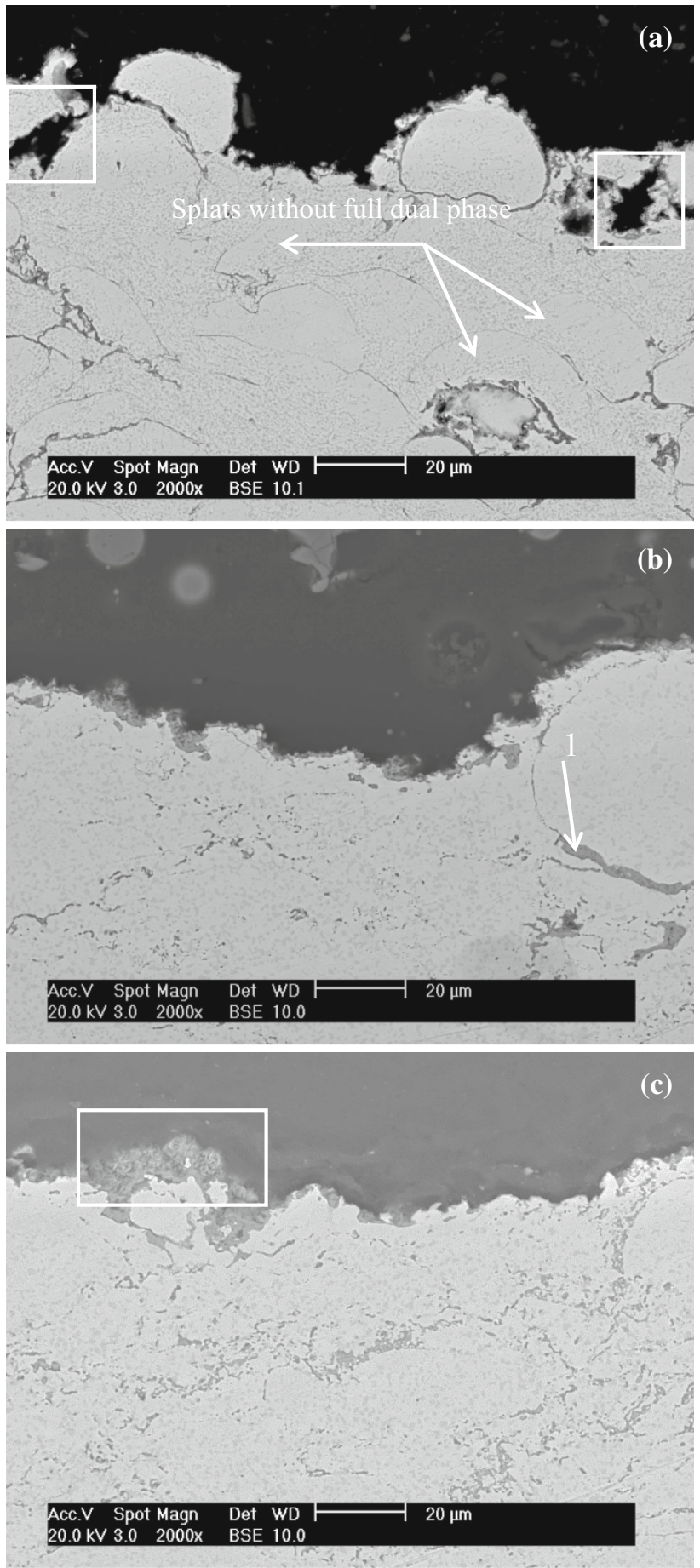

Fig. 12 Cross section of (a) coating \#1 (900:0.400), (b) coating \#2 (878:0.445) and (c) coating \#3 (920:0.470) after $100 \mathrm{~h}$ exposure

result in excessive oxidation of molten powder particles; however, the powders are injected in the downstream of the liquid-fueled HVOF spray gun and this excess oxygen does not contribute to increased oxidation of metallic coatings. The effect of total flow rate on in-flight particle temperature and velocity is less pronounced, although it was 
suggested that the particle velocity increases with increasing the total flow rate. Comparing the coating microstructure of coatings \#2 to \#3, the degree of particle deformation is similar in the cross-sectional images; however, the topography of the coatings shows splashing of splats, possibly due to higher impact energies of the splats in coating \#3. There was no obvious difference in porosity levels between coating \#2 and coating \#3 in MIP analysis. The major difference between these two coatings was the oxygen content. Coating \#3 had almost twice the level of oxygen than that of coating \#2, which suggests the particles went through more in-flight oxidation. Although, both the coatings \#2 and \#3 were sprayed at similar oxygen-fuel ratio, the higher total flow rate contributed to this higher level of oxidation. The most plausible explanation is that the particles achieved a higher temperature that resulted in this higher degree of oxidation.

\section{Oxidation of HVOF Thermal-Sprayed Coating}

High-temperature oxidation test was used as a means to differentiate the performance of the three coatings with different levels of oxides and porosity. Table 3 summarizes the process parameter, porosity, oxygen content, and oxidation performance of all coatings. Coating \#1 had high porosity but low oxide content, coating \#2 had medium porosity and medium oxide content, and coating \#3 had low porosity but high oxide content. The kinetic behavior of all three coatings followed a two-stage mechanism, as previously reported in liquid and gas fuel HVOF-sprayed Ni50Cr coatings (Ref 16). Usually, the parabolic oxidation law is applied to those metal and alloys that can generate a uniform and dense oxide scale at the surface and thereby oxidant ion diffusion through the scale is the dominant step in oxidation reactions (Ref 1). However, the squared of the mass change versus time data in Fig. 8(b) does not show a single straight line which is characteristic of the parabolic behavior in air oxidation. This is possibly due to the lack of a continuous and dense oxide scale at the surface of the coating. Indeed, the oxides grown after 1 and $10 \mathrm{~h}$ in (Fig. 9a and b) are rather thin and the cross-sectional images showed internal oxidation of the coatings. It is hypothesized that the thin and possibly discontinuous oxides grown on the surface could not lead to a solely diffusion controlled oxidation phenomenon, which allowed ingress of oxygen through surface connected pores resulting in internal oxidation. As a consequence, both top surface oxide and the internal oxidation progressed during the $4 \mathrm{~h}$ TGA exposure resulting in this two-stage oxidation behavior, which deviated from the typical parabolic oxidation phenomenon. The thin surface oxide reduced the opportunity for oxygen to come in and contact with the coating surface and thereby slowed down the oxidation rates that resulted in lower oxidation rates in the second stage for all three coatings.

The quantitative results from this study can be compared with the bulk alloys reported in literature of similar compositions. Calvarin et al. (Ref 25) reported a two-stage oxidation kinetic behavior of $\mathrm{Ni} 20 \mathrm{Cr}$ at $700{ }^{\circ} \mathrm{C}$ where the first stage obeys a parabolic law and the second stage follows a complete law (with a linear and parabolic com-

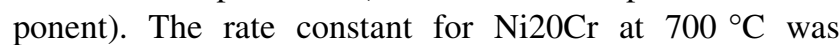
$3.8 \times 10^{-4} \mathrm{mg}^{2} \mathrm{~cm}^{-4} \mathrm{~min}^{-1}$ for the first stage and $2.6 \times 10^{-7} \mathrm{mg}^{2} \mathrm{~cm}^{-4} \mathrm{~min}^{-1}$ for the second stage. Another study by Essuman et al. (Ref 26) reported the oxidation kinetic of $\mathrm{Ni} 25 \mathrm{Cr}$ in $\mathrm{Ar}-20 \% \mathrm{O}_{2}$ at $1100{ }^{\circ} \mathrm{C}$, which is $1.66 \times 10^{-4} \mathrm{mg}^{2} \mathrm{~cm}^{-4} \mathrm{~min}^{-1}$. In this study, the rate constants for coating \#2 in both stages $\left(2-6 \times 10^{-4}\right.$ $\left.\mathrm{mg}^{2} \mathrm{~cm}^{-4} \mathrm{~min}^{-1}\right)$ and coating \#3 (4-7 $\times 10^{-4} \mathrm{mg}^{2}$ $\mathrm{cm}^{-4} \mathrm{~min}^{-1}$ ) are broadly in line with those reported data. The surface morphology and the microstructure of the HVOF thermal-sprayed coating vary from the bulk alloys, so some degree of variation is expected. However, the rate constant for coating \#1 is an order of magnitude higher (1.1-1.6 $\left.\times 10^{-3} \mathrm{mg}^{2} \mathrm{~cm}^{-4} \mathrm{~min}^{-1}\right)$ than those of coatings \#2 and \#3. Coating \#1 had the lowest amount of oxide but the highest level of porosity. The porosity of the coating allowed oxygen to seep through the coating, which oxidized the splat boundaries, indeed that was observed at the poor particle-particle interface after the long-term exposure (Fig. 12). The pre-existing oxide, $\mathrm{NiO}$, from the as-sprayed coatings can also combine with $\mathrm{Cr}_{2} \mathrm{O}_{3}$ to $\mathrm{NiCr}_{2} \mathrm{O}_{4}$ spinel and thereby promotes more chromium to oxidize, finally absorbing oxygen from air and contributing to the kinetic

Table 3 Main process parameters, porosity, oxygen content and oxidation performance of all three coatings

\begin{tabular}{lccccc}
\hline Coating & $\begin{array}{c}\text { Oxygen } \\
\text { stoichiometry, } \%\end{array}$ & $\begin{array}{c}\text { Total mass } \\
\text { flow rate, g s }\end{array}$ & $\begin{array}{c}\text { Porosity, } \\
\text { vol.\% }\end{array}$ & $\begin{array}{c}\text { Oxygen } \\
\text { content, wt.\% }\end{array}$ & $\begin{array}{c}\text { Air oxidation mass } \\
\text { gain, mg cm }\end{array}$ \\
\hline$\# 1$ & 117 & 26.5 & 4.83 & 0.257 & 0.5340 \\
$\# 2$ & 100 & 26.5 & 2.30 & 0.464 & 0.2695 \\
3 & 100 & 28 & 1.59 & 0.944 & 0.3370 \\
\hline
\end{tabular}


behavior of as-sprayed coatings. The coating \#1 had the lowest amount of oxide, and hence oxidation of the preexisting oxides in the as-sprayed coating was not a major contributor. Also, at higher temperature diffusion takes place which can reduce the inter-splat porosity, but the exposure temperature in this study was not high enough and/or the time was not long enough as the splat boundaries are still visible in Fig. 12. The porosity of coating \#1 is almost two times higher than the rest of the coatings, and this high level of porosity is the key factor in this high parabolic rate constant. Now looking into the oxidation kinetics of coatings \#2 and \#3, the second stage rate constant of coating \#2 (Fig. 8b) is half of that of coating \#3, although both the coatings have similar rate constants during the first stage of oxidation. According to the MIP measurements, both the coatings have similar porosity levels and hence the main difference here is the level of oxides. Oxide content of coating \#3 is almost twice than that of coating \#2, which means there are much more oxides surrounding the splats in coating \#3. It has been reported in bulk high-chromium alloys (Cr wt.\% > 20\%) (Ref 1) that the previously formed oxides at the alloy surface can aggregate to form a dense chromia scale to prevent fresh metal surface underneath the scale to contact with oxidizing atmosphere (Ref 1). However, the oxides surrounding the splats in thermal spray coating do not have such a function since they are not continuous. In contrast to that, those oxides surrounding the splats can act as oxidizing ion transport path like pores so that fresh metal inside splats and splats underneath the several top layers can contact and react with oxidizing atmosphere, i.e., oxides inside thermal spray coating formed during spraying is detrimental to oxidation resistance of the coatings. In coatings with similar porosity levels, the lower level of oxides led to a better oxidation performance.

In addition, the morphology and the size of oxide grains at the top surface of three coatings can also result in different oxidation performance. Oxide grains at the top surface of coating \#2 are the largest in size (Fig. 11), which also means the density of the grain boundary is the lowest. Since oxidation ions and atoms have the highest diffusion rates at the grain boundary (Ref 27), reducing grain boundary density can slowdown the transport of oxidation ions and atoms and thereby retard further oxide scale growth. It should be noted that this effect can be only applied to those metals and alloys which can form protective oxidation scales.

At high temperature, a continuous and dense oxide film can protect the sample surface from further oxidation. According to Wagner's oxidation theory, the formation of an external oxidation scale is a function of selective oxidation of active elements, such as $\mathrm{Cr}$ (Ref 28). Transient oxidation process takes place in commercial $\mathrm{Ni}-\mathrm{Cr}$ alloys at high temperature (Ref 29). For instance, in Ni20Cr alloy both $\mathrm{NiO}$ and $\mathrm{Cr}_{2} \mathrm{O}_{3}$ form and grow consequently covering the entire surface. $\mathrm{NiO}$ has a faster growth rate than $\mathrm{Cr}_{2} \mathrm{O}_{3}$ but it is thermodynamically less stable than $\mathrm{Cr}_{2} \mathrm{O}_{3}$ (Ref 25). However, in alloys with more than $20 \mathrm{wt} . \% \mathrm{Cr}$ selective oxidation of $\mathrm{Cr}$ takes place and the $\mathrm{Cr}_{2} \mathrm{O}_{3}$ is the main oxide found in the scale (Ref 30). Similarly, in this study $\mathrm{Cr}_{2} \mathrm{O}_{3}$ was the main oxidation product in all three coatings according to the XRD. $\mathrm{NiCr}_{2} \mathrm{O}_{4}$ spinel forms as the reaction product of $\mathrm{NiO}$ and $\mathrm{Cr}_{2} \mathrm{O}_{3}$. The formation of $\mathrm{NiO}$, $\mathrm{Cr}_{2} \mathrm{O}_{3}$ and $\mathrm{NiCr}_{2} \mathrm{O}_{4}$ along with the corresponding Gibbs free energies is reported below (Ref 31)

$$
\begin{aligned}
& 2 \mathrm{Cr}(\mathrm{s})+\frac{3}{2} \mathrm{O}_{2}(\mathrm{~g}) \rightarrow \mathrm{Cr}_{2} \mathrm{O}_{3}(\mathrm{~s}) \quad \Delta G=-1092.44+0.238 T \\
& \mathrm{Ni}(\mathrm{s})+\frac{1}{2} \mathrm{O}_{2}(\mathrm{~g}) \rightarrow \mathrm{NiO}(\mathrm{s}) \quad \Delta G=-232.45+0.0836 T \\
& \mathrm{NiO}(\mathrm{s})+\mathrm{Cr}_{2} \mathrm{O}_{3}(\mathrm{~s}) \rightarrow \mathrm{NiCr}_{2} \mathrm{O}_{4}(\mathrm{~s}) \quad \Delta G=-53.6+0.0084 T
\end{aligned}
$$

In this study, $\mathrm{NiO}$ and $\mathrm{NiCr}_{2} \mathrm{O}_{4}$ in small quantities were detected only in coating \#2 after $100 \mathrm{~h}$. The oxidation performance of this coating for 1,10 , and $100 \mathrm{~h}$ was reported in a previous publication (Ref 16). It was concluded that $\mathrm{NiCr}_{2} \mathrm{O}_{4}$ peaks appear after $10 \mathrm{~h}$ and $\mathrm{NiO}$ after $100 \mathrm{~h}$ in the oxidation. This is in line with the findings of the spinel formation from the reaction of $\mathrm{NiO}$ and $\mathrm{Cr}_{2} \mathrm{O}_{3}$. It is not clear at this stage why this mechanism takes place only in coating \#2 but not in coatings \#1 and \#3 along with the feedstock powder. The oxygen analysis quantified the oxygen contents in the as-sprayed coatings; however, it was not possible to identify the phases due to an absence of oxide $\left(\mathrm{Cr}_{2} \mathrm{O}_{3}, \mathrm{NiO}\right.$ and $\left.\mathrm{NiCr}_{2} \mathrm{O}_{4}\right)$ corresponding peaks in XRD scans. Also, the phase composition of oxides cannot be obtained from the EDX results. It is plausible that more $\mathrm{NiO}$ formed in the as-sprayed coating \#2 due to its processing history. This excess $\mathrm{NiO}$ reacts with the $\mathrm{Cr}_{2} \mathrm{O}_{3}$ formed during the oxidation tests to support the growth of $\mathrm{Ni}-\mathrm{Cr}$ spinel.

The bulk microstructure of coatings \#2 is also different from the remaining coatings and the feedstock powder after $100 \mathrm{~h}$ of oxidation. There is no $\alpha$-Cr peak present in the coating \#2 after the high-temperature oxidation, while coatings \#1 and \#3 still retain the $\alpha$-Cr phase. This unique behavior of coating \#2 can be explained with the fact that more chromium was consumed for the creation of $\mathrm{Cr}_{2} \mathrm{O}_{3}$ and $\mathrm{NiCr}_{2} \mathrm{O}_{4}$ spinel. As previously explained, $\mathrm{NiO}$ combine with $\mathrm{Cr}_{2} \mathrm{O}_{3}$ to form $\mathrm{NiCr}_{2} \mathrm{O}_{4}$ spinel. Formation of spinel consumes $\mathrm{Cr}_{2} \mathrm{O}_{3}$, which is the reaction product of the oxidation of chromium. The reduction of the reaction product will promote reaction in forward direction, i.e., more chromium will be consumed due to the generation of spinel. This is hypothesized as one of the key reasons that no $\alpha$-Cr phase was detected in the coating \#2 after the oxidation. 


\section{Conclusions}

In the present study, Ni50Cr feedstock powder was deposited using a liquid-fueled HVOF thermal spray onto a modified 9Cr (ASME P92) boiler steel with three processing parameters. The microstructure and porosity of the coatings were examined in detail. The high-temperature oxidation kinetics of the coatings was examined in shortterm TGA in the air and the phase evolution of the coatings was studied in long-term air oxidation test. Following conclusions can be drawn:

- All three as-sprayed coatings consist of $\gamma-(\mathrm{Ni}, \mathrm{Cr})$ and $\alpha$ $\mathrm{Cr}$ phases. The oxygen content of all three coatings was measured using a precision combustion analysis, and the values were as follows: coating \#1 0.257 wt.\%, coating \#2 0.464 wt.\% and coating \#3 0.944 wt.\%, respectively.

- All oxygen stoichiometries used in this study were all above $100 \%$ to make sure complete combustion of fuel. Coatings sprayed using lower oxygen stoichiometry (100\%) showed lower porosities (2.30 and 1.59 vol.\%) than that of the coatings sprayed using $117 \%$ oxygen stoichiometry (4.83 vol.\% porosity) due to a higher degree of deformation of the splats upon impact. Effect of total mass flow rate on the porosity of as-sprayed coatings is not as obvious as that of oxygen stoichiometry; however, its effect on the oxide content of coatings is apparent, i.e., higher total mass flow rate leads to higher oxide content in coating.

- Oxidation kinetic behavior study indicates that the coating \#2 shows the best oxidation resistance, which has medium level of porosity and medium level of oxide content. Lower porosity is the main reason that the oxidation performance of coating \#2 is better than that of coating \#1. The higher level of oxides in coating \#3 resulted in the inferior oxidation performance of this coating.

- In all three coatings, oxide scales covered the coating surface after $1 \mathrm{~h}$ exposure in air at $700{ }^{\circ} \mathrm{C}$. The oxide grains at the surface of coating \#2 were the largest which contributed to the best oxidation resistance (due to reduced grain boundaries) since grains boundary is the main transport path for the oxidation species. Only in coating \#2 after $100 \mathrm{~h}$ of oxidation, $\mathrm{NiCr}_{2} \mathrm{O}_{4}$ and $\mathrm{NiO}$ were identified and the $\alpha$ phase in the coating disappeared due to the consumption of $\mathrm{Cr}$ to create $\mathrm{NiCr}_{2} \mathrm{O}_{4}$.

Open Access This article is distributed under the terms of the Creative Commons Attribution 4.0 International License (http://crea tivecommons.org/licenses/by/4.0/), which permits unrestricted use, distribution, and reproduction in any medium, provided you give appropriate credit to the original author(s) and the source, provide a link to the Creative Commons license, and indicate if changes were made.

\section{References}

1. N. Birks, G.H. Meier, and F.S. Pettit, Introduction to the High Temperature Oxidation of Metals, Cambridge University Press, Cambridge, 2006

2. T. Hussain, T. Dudziak, N. Simms, and J. Nicholls, Fireside Corrosion Behavior of HVOF and Plasma-Sprayed Coatings in Advanced Coal/Biomass Co-Fired Power Plants, J. Therm. Spray Technol., 2013, 22(5), p 797-807

3. M. Oksa, P. Auerkari, J. Salonen, and T. Varis, Nickel-based HVOF Coatings Promoting High Temperature Corrosion Resistance of Biomass-Fired Power Plant Boilers, Fuel Process. Technol., 2014, 125, p 236-245

4. S. Bluni and A. Marder, Effects of Thermal Spray Coating Composition and Microstructure on Coating Response and Substrate Protection at High Temperatures, Corrosion, 1996, 52(3), p 213-218

5. H. Al-Fadhli, J. Stokes, M. Hashmi, and B. Yilbas, The ErosionCorrosion Behaviour of High Velocity Oxy-Fuel (HVOF) Thermally Sprayed Inconel-625 Coatings on Different Metallic Surfaces, Surf. Coat. Technol., 2006, 200(20), p 5782-5788

6. M. Uusitalo, P. Vuoristo, and T. Mäntylä, High Temperature Corrosion of Coatings and Boiler Steels in Reducing ChlorineContaining Atmosphere, Surf. Coat. Technol., 2002, 161(2), p 275-285

7. H. Edris, D. McCartney, and A. Sturgeon, Microstructural Characterization of High Velocity Oxy-Fuel Sprayed Coatings of Inconel 625, J. Mater. Sci., 1997, 32(4), p 863-872

8. E. Toyserkani, A. Khajepour, and S.F. Corbin, Laser Cladding, CRC Press, Boca Raton, 2004

9. K. Choy, Chemical Vapour Deposition of Coatings, Prog. Mater Sci., 2003, 48(2), p 57-170

10. O. Brandt, Mechanical Properties of HVOF Coatings, J. Therm. Spray Technol., 1995, 4(2), p 147-152

11. T. Hanson and G. Settles, Particle Temperature and Velocity Effects on the Porosity and Oxidation of an HVOF CorrosionControl Coating, J. Therm. Spray Technol., 2003, 12(3), p 403-415

12. C.M. Hackett, The Gas Dynamics of High-Velocity Oxy-Fuel Thermal Sprays, Ph.D. Thesis, The Pennsylvania State University, 1996

13. H. Voggenreiter, H. Huber, H.-J. Spies, and H. Baum, HVOFsprayed Alloy In 718- The Influence of Process Parameters on the Microstructure and Mechanical Properties, Thermal spray: A united forum for scientific and technological advances, 1998, p 895-900

14. K. Dobler, H. Kreye, and R. Schwetzke, Oxidation of Stainless Steel in the High Velocity Oxy-Fuel Process, J. Therm. Spray Technol., 2000, 9(3), p 407-413

15. S. Gu, D. McCartney, C. Eastwick, and K. Simmons, Numerical Modeling of In-Flight Characteristics of Inconel 625 Particles During High-Velocity Oxy-Fuel Thermal Spraying, J. Therm. Spray Technol., 2004, 13(2), p 200-213

16. B. Song, Z. Pala, K.T. Voisey, and T. Hussain, Gas and LiquidFueled HVOF Spraying of Ni50Cr Coating: Microstructure and High Temperature Oxidation, Surf. Coat. Technol., 2016. doi:10. 1016/j.surfcoat.2016.07.046

17. D. Zhang, S.J. Harris, and D.G. McCartney, Microstructure Formation and Corrosion Behaviour in HVOF-Sprayed Inconel 625 Coatings, Mater. Sci. Eng. A, 2003, 344(1-2), p 45-56

18. K.K. Kuo, Principles of Combustion, 2nd ed., John Wiley \& Sons, Inc., 2005, p 224-244

19. L. Pawlowski, The Science and Engineering of Thermal Spray Coatings, Wiley, Chichester, 2008

20. T. Sundararajan, S. Kuroda, T. Itagaki, and F. Abe, Steam Oxidation Resistance of Ni-Cr Thermal Spray Coatings on 9Cr-1Mo Steel. Part 2: 50Ni-50Cr, ISIJ Int., 2003, 43(1), p 104-111 
21. T. Hussain, D.G. McCartney, P.H. Shipway, and T. Marrocco, Corrosion Behavior of Cold Sprayed Titanium Coatings and Free Standing Deposits, J. Therm. Spray Technol., 2011, 20(1-2), p 260-274

22. J. Saaedi, T. Coyle, S. Mirdamadi, H. Arabi, and J. Mostaghimi, Phase Formation in a Ni-50Cr HVOF Coating, Surf. Coat. Technol., 2008, 202(24), p 5804-5811

23. R. Kamali and A.R. Binesh, The Importance of Sensitive Parameters Effect on the Combustion in a High Velocity OxygenFuel Spray System, Int. Commun. Heat Mass Transf., 2009, 36(9), p 978-983

24. S. Wanphut, Optimisation of HVOF Sprayed MCrAlY Coatings for Gas Turbines, University of Nottingham

25. G. Calvarin, R. Molins, and A. Huntz, Oxidation Mechanism of $\mathrm{Ni}-20 \mathrm{Cr}$ Foils and its Relation to the Oxide-Scale Microstructure, Oxid. Met., 2000, 53(1-2), p 25-48

26. E. Essuman, G. Meier, J. Zurek, M. Hänsel, T. Norby, L. Singheiser, and W. Quadakkers, Protective and Non-Protective Scale
Formation of NiCr Alloys in Water Vapour Containing High-and Low-pO 2 Gases, Corros. Sci., 2008, 50(6), p 1753-1760

27. E.A. Polman, T. Fransen, and P.J. Gellings, Oxidation Kinetics of Chromium and Morphological Phenomena, Oxid. Met., 1989, 32(5), p 433-447

28. D.J. Young, High Temperature Oxidation and Corrosion of Metals, Elsevier, Amsterdam, 2008

29. B. Kear, F. Pettit, D. Fornwalt, and L. Lemaire, On the Transient Oxidation of a Ni-15Cr-6Al Alloy, Oxid. Met., 1971, 3(6), p 557569

30. A. Ul-Hamid, A TEM Study of the Oxide Scale Development in Ni-Cr Alloys, Anti Corros. Methods Mater., 2004, 51(3), p 216 222

31. E.B. Rudnyi, E.A. Kaibicheva, L.N. Sidorov, M.T. Varshavskii, and A.N. Men (Ion + Molecule) Equilibrium Technique Applied to the Determination of the Activities of $\mathrm{Cr} 2 \mathrm{O} 3$ and NiO. Standard Molar Gibbs Energy of Formation of NiCr2O4, J. Chem. Thermodyn., 1990, 22(7), p 623-632 